\title{
Politik Identitas dalam Pemilihan Presiden 2019 (Analisis Framing Pemberitaan Kampanye Pilpres 2019 pada Medcom.id)
}

\author{
Laylia Farida, M. Gafar Yoedtadi \\ layliafarida@gmail.com gafary@fikom.untar.ac.id \\ Fakultas Ilmu Komunikasi Universitas Tarumanagara
}

\begin{abstract}
2019 is one of the years which is considered quite a sense for the people of Indonesia, this year the presidential and vice presidential elections reunite Joko Widodo and Prabowo Subianto as presidential candidates. During the 2019 presidential election campaign, the issue of identity politics strengthened in the community. Political actors often use an identity to attract the attention and support of potential voters. The media which are supposed to be independent are actually trapped in the issue of identity politics. Reporting on online media is often influenced by the ideology and interests of media that are reflected in the framing of the news carried out by that media. This Study aims to describe the framing carried out by medcom.id in reporting the 2019 presidential election campaign. This study uses a qualitative approach with framing analysis from Robert $N$. Entman. The results of this study indicate that medcom.id is proven to be framing using identity politics in reporting the 2019 presidential election campaign. Identity politics framing conducted by medcom.id is news containing SARA (Ethnicity, Religion, Ancestry, and Group of People)
\end{abstract}

Keywords: 2019 presidential election campaign, identity politics, framing analysis.

\begin{abstract}
Abstrak
Tahun 2019 merupakan salah satu tahun politik yang dinilai cukup panas bagi masyarakat Indonesia, pada tahun ini pemilihan presiden dan wakil presiden kembali mempertemukan Joko Widodo dan Prabowo Subianto sebagai calon presiden. Pada kampanye Pilpres 2019 kemarin, isu politik identitas menguat di masyarakat. Para aktor politik sering kali menggunakan sebuah identitas untuk menarik perhatian serta dukungan calon pemilihnya di masyarakat. Media yang seharusnya independen justru terjebak dalam isu politik identitas tersebut. Pemberitaan pada media online seringkali dipengaruhi oleh ideologi dan kepentingan pemilik media yang tergambar pada pembingkaian berita yang dilakukan oleh media tersebut. Penelitian ini bertujuan untuk menggambarkan pembingkaian yang dilakukan oleh portal berita media online medcom.id dalam memberitakan kampanye pemilihan presiden 2019. Penelitian ini menggunakan pendekatan kualitatif dengan analisis framing Robert $\mathrm{N}$. Entman. Hasil penelitian menunjukkan bahwa medcom.id terbukti melakukan pembingkaian dengan menggunakan politik identitas dalam pemberitaan kampanye Pilpres 2019. Pembingkaian politik identitas yang dilakukan oleh medcom.id adalah pemberitaan yang mengandung SARA (suku, agama, ras dan antar golongan).
\end{abstract}

Kata Kunci: politik identitas, analisis framing, kampanye pilpres 2019.

\section{Pendahuluan}

Tahun 2019 merupakan salah satu tahun politik yang dinilai cukup panas bagi masyarakat Indonesia, pada tahun ini pemilihan presiden dan wakil presiden kembali mempertemukan Joko Widodo dan Prabowo Subianto sebagai calon presiden. Setelah 
sebelumnya pada tahun 2014 Pilpres tersebut dimenangkan oleh Joko Widodo dengan wakilnya saat itu Jusuf Kalla. Pada pemilihan presiden dan wakil presiden periode keduanya, Jokowi menggaet Ma'ruf Amin sebagai wakil presidennya, sedangkan Prabowo Subianto memilih untuk berpasangan dengan Sandiaga Uno yang saat itu menjabat sebagai wakil gubernur DKI Jakarta.

Pemilihan Ma'ruf Amin sebagai wakil presiden oleh Joko Widodo disebabkan oleh menguatnya politik identitas terhadap situasi politik di Indonesia (Sonny, 2019: 454). Hal tersebut dikarenakan Ma'ruf Amin yang merupakan salah satu ulama besar dan saat itu menjabat sebagai ketua Majelis Ulama Indonesia (MUI). Selain itu, dari kubu Prabowo - Sandi, mereka mengklaim bahwa pihaknya juga didukung oleh sejumlah ulama di Indonesia, hal ini semakin memperkuat adanya politik identitas pada kedua paslon presiden dan wakil presiden. Sejak saat itu unsur politik identitas pun banyak ditemukan dalam berbagai kesempatan saat masa kampanye yang dimulai pada 23 September 2018 hingga berakhir pada 13 April 2019, sedangkan pemilihan presiden sendiri dilakukan pada 17 April 2019.

Pemberitaan seputar kampanye Pilpres 2019 yang mengandung unsur politik identitas banyak ditemukan di media massa cetak maupun elektronik dan media online yang merupakan new media, salah satunya adalah medcom.id yang merupakan transformasi dari metrotvnews.com sebagai media online milik Media Group. Dalam pemberitaan seputar kampanye Pilpres 2019 yang dilakukan oleh medcom.id, penulis menemukan beberapa berita yang dimuat mengandung unsur politik identitas yang dilakukan selama masa kampanye berlangsung, kemudian di frame oleh medcom.id sehingga dapat menggiring opini pembacanya. Media online dipilih oleh penulis karena kemudahan dan kecepatan untuk diakses kapan saja oleh pembaca. Selain itu, berita pada media online dapat dibaca berulang-dan menjangkau khalayak yang lebih luas, bersifat aktual dan up to date.

Berdasarkan uraian tersebut, rumusan masalah pada penelitian ini adalah bagaimana framing yang dilakukan oleh medcom.id terhadap pemberitaan yang mengandung unsur politik identitas selama masa kampanye pilpres 2019. Penelitian ini bertujuan untuk mengetahui bagaimana framing yang dilakukan oleh medcom.id terhadap pemberitaan yang mengandung unsur politik identitas selama masa kampanye pemilihan presiden 2019.

Pada penelitian ini, penulis akan membahas secara lebih berita pada media online. Romli (2012) menjelaskan bahwa dalam penulisannya berita online pada dasarnya sama dengan berita pada media cetak, perbedaannya terletak pada kecepatan dalam meng-update berita, kemudahan akses bagi pembaca, serta mempunyai integritas dengan adanya unsur multimedia.

Shoemaker dan Reese (Krisdinanto, 2014), menjelaskan tentang teori hirarki pengaruh terhadap isi media merupakan teori tentang isi media (media content) serta faktor-faktor pengaruh yang membentuknya. Shoemaker-Reese menjelaskan bahwa pemberitaan pada media dipengaruhi oleh faktor internal dan eksternal. Faktor internal pada konten media berhubungan dengan kepentingan pemilik media, wartawan sebagai pencari berita, serta rutinitas organisasi media. Sedangkan faktor eksternal media berhubungan dengan masyarakat pengiklan, serta pemerintah. Hal tersebut menjelaskan bahwa, isi pada media merupakan hasil dari tekanan pada dalam maupun luar organisasi media. Mengacu pada teori tersebut, Shoemaker-Reese, seperti dikutip (Yoedtadi dan Pribadi, 2017) membuat model teori hierarki pengaruh terhadap isi media, yakni (1) pengaruh individual atau pekerja media (2) pengaruh rutinitas media (3) pengaruh organisasional (4) pengaruh dari luar organisasi (5) pengaruh ideologi. 
Framing merupakan cara seorang wartawan untuk memberitakan sebuah peristiwa berdasarkan pada sudut pandang yang ingin disampaikan kepada pembaca. Framing lebih melihat cara bagaimana media bercerita atas peristiwa yang terjadi serta melihat bagaimana media mengkonstruksi sebuah berita yang ada karena fakta atau peristiwa merupakan hasil dari konstruksi (Eriyanto, 2008: 19). Framing merupakan sebuah metode yang digunakan untuk melihat cara media bercerita terhadap suatu peristiwa. Cara bercerita tersebut digambarkan pada "cara melihat" pada realitas yang dijadikan berita. Hasil akhir dari konstruksi realitas dipengaruhi oleh "Cara melihat" tersebut. Framing memiliki dua esensi utama tersebut yaitu; Pertama, bagaimana peristiwa dimaknai. Aspek tersebut berhubungan dengan bagian mana dari suatu peristiwa yang akan diliput dan bagian mana yang tidak diliput. Kedua, bagaimana fakta tersebut ditulis, bagaimana pemakaian kata, kalimat, serta gambar untuk mendukung gagasan (Eriyanto, 2011).

Sedangkan politik identitas sendiri menurut Lukmantoro (Buchari, 2014) politik identitas merupakan sebuah tindakan politis dari anggota suatu kelompok karena memiliki kesamaan identitas maupun karakteristik, baik berbasiskan pada etnisitas, ras, keagamaan dan gender dengan mengedepankan kepentingankepentingan dari kelompok tersebut. Politik identitas pada dasarnya merupakan upaya yang digunakan untuk mencapai suatu kekuasaan tertentu dalam panggung politik serta kehidupan seseorang, di mana keberadaan serta pengakuan wakil-wakil dari kelompok merupakan suatu bagian penting dari perjuangan politik yang dilakukan demi kepentingan kelompok etnisnya.

\section{Metode Penelitian}

Penelitian ini bersifat deskriptif kualitatif. Penelitian ini akan menghasilkan data deskriptif yang dapat menjelaskan bagaimana pembingkaian peristiwa pada kehidupan sosial terutama dalam hal komunikasi. Penulis menggunakan metode ini untuk dapat membahas analisis framing terhadap unsur politik identitas dalam pemberitaan kampanye Pilpres 2019. Alat yang digunakan untuk menganalisis peristiwa dalam penelitian ini adalah analisis framing milik Robert N. Entman. Dalam konsepsi Entman, framing merupakan pemberian suatu definisi, memberikan penjelasan, melakukan evaluasi serta rekomendasi dalam suatu wacana yang digunakan untuk menekankan sebuah kerangka berpikir tertentu terhadap suatu peristiwa yang sedang diwacanakan. (Eriyanto, 2011)

Subyek dari penelitian ini merupakan portal berita media online yaitu medcom.id. Medcom.id dipilih oleh penulis sebagai subyek penelitian didasarkan pada latar belakang dari media tersebut yang menjadi salah satu faktor adanya pembingkaian dalam pemberitaannya. Sedangkan objek dalam penelitian ini adalah artikel berita terkait unsur politik identitas selama masa kampanye Pilpres 2019 sejak 23 September 2018 hingga 13 April 2019.

Penulis melakukan pengumpulan data yang nantinya akan diolah menjadi sebuah kesimpulan penelitian, dalam hal ini penulis melakukan teknik pengumpulan data sebagai berikut; Data primer adalah data yang telah dikumpulkan secara pribadi oleh penulis, data yang akan diolah pada penelitian ini adalah data yang berasal dari pemberitaan-pemberitaan pada medcom.id yang mengandung unsur politik identitas selama masa kampanye Pilpres 2019. Sedangkan penulis mengumpulkan dan melengkapi data sekunder pada penelitian ini dengan menggunakan metode studi pustaka, penulis menggunakan referensi buku, jurnal serta laporan penelitian untuk 
menjadi pedoman penulisan bagi peneliti untuk melakukan olah data dalam rangka melakukan analisis framing pada pemberitaan di artikel medcom.id.

Peneliti menggunakan analisis framing sebagai teknik dalam menganalisis data penelitian. Analisis framing digunakan untuk melihat bagaimana media mengkonstruksikan sebuah realitas yang ada. Analisis framing digunakan untuk melihat bagaimana sebuah peristiwa dimaknai kemudian dibingkai oleh media. (Eriyanto, 2011). Peneliti menggunakan analisis framing yang diperkenalkan oleh Robert N. Entman. Entman mengemukakan empat perangkat untuk melakukan analisis framing (Eriyanto, 2011: 233) yaitu: defines problem (pendefinisian masalah), diagnose causes (memperkirakan masalah atau sumber masalah), make moral judgement (membuat keputusan moral), dan treatment recommendation (menekankan penyelesaian).

\section{Hasil Temuan dan Diskusi}

Dalam penelitian ini, penulis melakukan analisis sesuai dengan tujuan penelitian serta menggunakan metode penelitian kualitatif deskriptif dengan menggunakan analisis framing model Robert N. Entman. Melalui pendekatan deskriptif, penulis memberikan penjelasan dari setiap pemberitaan yang dimuat oleh medcom.id, mengenai pemberitaan seputar kampanye Pilpres 2019 yang mengandung unsur politik identitas. Berikut ini adalah penjelasan mengenai latar belakang media yang diambil untuk dijadikan objek penelitian, yaitu medcom.id.

Medcom.id merupakan transformasi dari metrotvnews.com, yaitu sebuah portal media online yang dikelola oleh PT Citra Multimedia Indonesia yang merupakan bagian dari Media Group. Media Group merupakan perusahaan yang mengelola Metro TV serta surat kabar harian Media Indonesia milik Surya Paloh yang juga ketua umum partai Nasional Demokrat (Nasdem).

\begin{tabular}{lll} 
NO & JUDUL ARTIKEL & TANGGAL TERBIT \\
\hline 1. & Ma'ruf: Saya Punya Darah Madura dan Arosbaya & 19 Oktober 2018 \\
2. & Dunia Islam Mengakui Jokowi & 19 Oktober 2018 \\
3. & Jokowi Mencintai Kiai dan Santri & 30 Oktober 2018 \\
4. & Ma'ruf Amin Yakin Raup 70 Persen Suara & 03 November 2018 \\
& di Banten & \\
5. & Jokowi Juga Berdarah Boyolali & 05 November 2018 \\
6. & Target Menang 60\% di Aceh & 15 Desember 2018 \\
7. & Ma'ruf Dapat Dukungan Bobotoh & 02 Januari 2019 \\
8. & Ma'ruf Segera Safari ke Tangerang & 04 Januari 2019 \\
9. & Jokowi-Ma'ruf bakal Rebut Jawa Barat & 21 Januari 2019 \\
10. & Ma'ruf Bertandang ke Pondok Pesantren & 05 Februari 2019 \\
& Al-Hidayat &
\end{tabular}

Analisis Framing Berita 1 "Ma'ruf: Saya Punya Darah Madura dan Arosbaya"

Redaksi dalam artikel tersebut menonjolkan ucapan Ma'ruf yang mengatakan bahwa dirinya masih memiliki darah Arosbaya. Hal tersebut merupakan salah satu bentuk dari politik identitas untuk meraih dukungan dan simpati dari tamu yang hadir dalam acara tersebut serta dukungan dari warga Madura. Selain itu, redaksi juga menambahkan silsilah dari Ma'ruf Amin untuk mendukung pernyataan tersebut. 


\section{Analisis Framing Berita 2 "Dunia Islam Mengakui Jokowi"}

Artikel tersebut sesuai dengan teori framing menurut Eriyanto pada media yang mengatakan bahwa media saat ini mengkonstruksi realitas yang ada. Berita ini termasuk dalam bentuk politik identitas yang tidak langsung, karena media menonjolkan fakta yaitu prestasi Presiden Joko Widodo yang masuk dalam daftar 50 muslim berpengaruh di dunia oleh RISSC (Royal Islamic Strategic Studies Center). Hal ini bertujuan agar menarik dukungan dan simpati suatu agama dengan menonjolkan fakta-fakta yang ada.

\section{Analisis Framing Berita 3 "Ma'ruf Amin: Jokowi Mencintai Santri"}

Pada artikel tersebut, redaksi mengulang pernyataan dari Ma'ruf yang mengatakan bahwa Jokowi memilih dirinya karena mencintai santri dan kiai. Hal tersebut merupakan politik identitas karena santri dan kiai bagian dari agama islam. Selain itu, redaksi juga menambahkan pernyataan dari Ma'ruf yang mengatakan bahwa Jokowi menetapkan Hari Santri Nasional pada 22 Oktober sebagai bentuk kecintaannya terhadap para santri dan kiai.

\section{Analisis Framing Berita 4 "Ma'ruf Amin Yakin Raup 70 Persen Suara di Banten"}

Pernyataan Ma'ruf dalam artikel tersebut yang mengatakan bahwa dirinya yakin dipilih oleh warga Banten karena merupakan putra daerah Banten Hal tersebut merupakan bentuk dari politik identitas yang diucapkan untuk mendapat dukungan dan simpati dari masyarakat setempat berdasarkan kesamaan ras atau suku antara Ma'ruf dengan warga Banten.

\section{Analisis Framing Berita 5 "Jokowi Juga Berdarah Boyolali"}

Dalam artikel tersebut ucapan Jokowi yang mengatakan bahwa dirinya juga memiliki darah Boyolali merupakan bentuk politik identitas. Selain itu, redaksi juga menambahkan silsilah keluarga Jokowi yang berasal dari Boyolali. Hal ini dilakukan agar menarik simpati serta dukungan dari masyarakat Boyolali serta menunjukkan rasa simpati kepada masyarakat Boyolali yang sempat kecewa dengan ucapan lawan politik Jokowi tentang kasus tampang Boyolali.

\section{Analisis Framing Berita 6 "Target Menang 60\% di Aceh"}

Pernyataan Jokowi dalam artikel tersebut yang mengatakan bahwa dirinya pernah tinggal di Aceh merupakan bentuk dari politik identitas. Hal tersebut ditonjolkan oleh redaksi dengan tujuan untuk mendapatkan dukungan dari kelompok tersebut karena adanya persamaan antara Jokowi dengan warga Aceh dan dapat mengerti Bahasa Aceh.

\section{Analisis Framing Berita 7 "Ma'ruf Dapat Dukungan Bobotoh"}

Redaksi pada artikel ini menekankan bahwa Ma'ruf merupakan pendukung salah satu klub sepak bola Persib (Persatuan Sepak Bola Indonesia Bandung) berasal dari Jawa Barat. Selain itu, redaksi juga menambahkan pernyataan dari salah satu perwakilan klub yang menyatakan bahwa Ma'ruf merupakan sesepuh di kalangan masyarakat Sunda. Hal ini merupakan politik identitas karena ucapan Ma'ruf tersebut menyatakan bahwa dirinya adalah bagian dari suatu kelompok yaitu pendukung Persib. 


\section{Analisis Framing Berita 8 "Ma'ruf Segera Safari ke Tangerang"}

Pada artikel ini redaksi memilih untuk menonjolkan sudut pandang Ma'ruf yang menjadikan Tangerang sebagai prioritasnya melakukan kampanye karena Ma'ruf merupakan wapres yang berasal dari Tangerang. Hal tersebut merupakan salah satu bentuk politik identitas yang digunakan agar mendapatkan simpati serta dukungan dari warga Tangerang.

\section{Analisis Framing Berita 9 "Jokowi-Ma'ruf bakal Rebut Jawa Barat"}

Redaksi dalam artikel tersebut menonjolkan pernyataan dari Ma'ruf yang mengatakan bahwa dirinya merupakan wakil dari Jawa Barat dan memiliki darah keturunan Sunda. Hal tersebut merupakan politik identitas yang bertujuan untuk menarik dukungan dari warga Jawa Barat.

\section{Analisis Framing Berita 10 "Ma'ruf Bertandang ke Pondok Pesantren Al- Hidayat"}

Dalam artikel tersebut redaksi menekankan pernyataan yang mengatakan bahwa pihak Ma'ruf yang didukung oleh para kiai. Hal tersebut merupakan bentuk politik identitas. Kiai sendiri merupakan bagian dari Islam, sehingga penekanan dalam ucapan Ma'ruf tersebut dimaksudkan untuk memperoleh kepercayaan dan simpati dari pemeluk Islam.

Berdasarkan hasil dari analisis framing dan hasil wawancara yang dilakukan oleh peneliti, banyaknya pemberitaan yang mengandung isu politik identitas selama masa kampanye Pilpres 2019 pada media massa merupakan salah satu hal yang perlu dievaluasi, karena hal tersebut tidak sesuai dengan fungsi media, seperti yang dikatakan oleh bapak Agus Sudibyo selaku anggota dewan pers, masyarakat berhak untuk mendapatkan informasi yang sebenar-benarnya:

"Tanpa disengaja, media itu menjadi alat sebagai kepanjangan tangan dari para aktor politik, tanpa disengaja nah itu yang harusnya dievaluasikan, karena media itu sebenarnya tidak boleh menjadi sarana siapapun kecuali sarana publik untuk mendapatkan kebenaran."

\section{Simpulan}

Berdasarkan hasil analisis dan pembahasan yang telah dilakukan oleh penulis maka dapat disimpulkan bahwa; Dalam pemberitaan kampanye Pilpres 2019 medcom.id terbukti melakukan pembingkaian pada unsur politik identitas. Selain itu, medcom.id turut mendukung pernyataan para paslon dan pendukungnya yang mengandung unsur politik identitas dengan menambahkan informasi tentang kebenaran dari pernyataan tersebut pada setiap artikelnya. Dari hasil penelitian terhadap pembingkaian politik identitas yang dilakukan oleh medcom.id lebih banyak mengandung unsur penonjolan pada suku dan agama.

Pemilik medcom.id yang tergabung dalam partai politik dan juga berada dalam partai koalisi petahana pada Pilpres 2019 melakukan pembingkaian dengan politik identitas pada pemberitaan seputar kampanye Pilpres 2019. Hal tersebut cenderung dilakukan untuk menarik simpati masyarakat agar mendukung salah satu paslon yang berada di pihak medcom.id. 


\section{Terima Kasih}

Terima kasih kepada keluarga, sahabat dan teman yang telah memberikan dukungan serta semangat kepada penulis selama mengerjakan penelitian. Terima kasih kepada bapak Agus Sudibyo selaku narasumber yang sudah meluangkan waktunya untuk melakukan wawancara dengan peneliti. Terima kasih kepada pihak Fakultas dan rekan-rekan Fakultas yang telah berkontribusi dalam penelitian ini.

\section{Daftar Pustaka}

Azhar, M. Sholahadhin. (2018, 23 Oktober). Ma'ruf Amin: Jokowi Mencintai Santri. Diakses pada Oktober 27, 2019, dari medcom.id: https://www.medcom.id/pemilu/news-pemilu/Dkqq2Pnk-ma-ruf-aminjokowi-mencintai-santri

Azhar, M. Sholahadhin. (2019, 2 Januari). Ma'ruf Dapat Dukungan Bobotoh. Diakses pada Oktober 27, 2019, dari medcom.id: https://www.medcom.id/pemilu/news-pemilu/Obzqmr7N-ma-ruf-dapatdukungan-bobotoh

Azhar, M. Sholahadhin. (2019, 5 Februari). Ma'ruf Bertandang ke Pondok Pesantren Al-Hidayat. Diakses pada Oktober 27, 2019, dari medcom.id: https://www.medcom.id/pemilu/news-pemilu/5b2qD2aN-ma-ruf-bertandangke-pondok-pesantren-al-hidayat

Azizah, Nur. (2018, 3 November). Ma'ruf Amin Yakin Raup 70 Persen Suara di Banten. Diakses pada Oktober 27, 2019, dari medcom.id: https://www.medcom.id/pemilu/news-pemilu/aNrqLVaK-ma-ruf-amin-yakinraup-70-persen-suara-di-banten

Buchari, S. A. (2014). Kebangkitan Etnis Menuju Politik Identitas. Jakarta: Yayasan Pustaka Obor Indonesia.

Eriyanto. (2008). Analisis Framing: Konstruksi, Ideologi dan Politik Media. Yogyakarta: LkiS.

Eriyanto. (2011). Analisis Framing: Konstruksi, Ideologi, dan Politik Media. Yogyakarta: LkiS.

Fazli, Achmad Zulfikar. (2018, 4 November). Jokowi Juga Berdarah Boyolali. Diakses pada Oktober 27, 2019, dari medcom.id: https://www.medcom.id/pemilu/news-pemilu/wkBD8W0N-jokowi-jugaberdarah-boyolali

Gunawan, Depi. (2019, 21 Januari). Jokowi-Ma'ruf bakal Rebut Jawa Barat. Diakses pada Oktober 27, 2019, dari medcom.id: https://www.medcom.id/pemilu/news-pemilu/0kpzqAEN-jokowi-ma-rufbakal-rebut-jawa-barat

Krisdinanto, N. (2014). Anomali dan Teori Hirarki Pengaruh terhadap Isi Media. Jurnal Ilmiah Komunikasi, 3(1). 8-9.

Medcom.id. (2019). Tentang Kami. Diakses pada 8 Desember 2019, dari medcom.id: https://www.medcom.id/tentangkami

Media Indonesia. (2018, Desember 15). Target Menang 60\% di Aceh. Diakses pada Oktober 27, 2019, dari medcom.id: https://www.medcom.id/pemilu/newspemilu/Rb13mRIK-target-menang-60-di-aceh

Romli, K. (2016). Komunikasi Massa. Jakarta: PT Grasindo. 
Sonny. (2019). Peta Politik Identitas di Indonesia: Studi Terpilihnya K.H. Ma'ruf Amin Sebagai Bakal Cawapres Bakal Capres Inkumben Joko Widodo Pada Pilpres 2019. Jurnal Renaissance, 4(1). 443-445.

Sumantri, Arga. (2018, Oktober 19). Ma'ruf: Saya Punya Darah Madura dan Arosbaya. Diakses pada Oktober 2, 2019, dari medcom.id: https://www.medcom.id/pemilu/news-pemilu/GN12Xn2k-ma-ruf-saya-punyadarah-madura-dan-arosbaya

Sumantri, Arga. (2018, 19 Oktober). Dunia Islam Mengakui Jokowi. Diakses pada Oktober 2, 2019, dari medcom.id: https://www.medcom.id/pemilu/newspemilu/4ba2000k-dunia-islam-mengakui-jokowi

Sumantri, Arga. (2019, 4 Januari). Ma'ruf Segera Safari ke Tangerang. Diakses pada Oktober 27, 2019, dari medcom.id: https://www.medcom.id/pemilu/newspemilu/ZkezMz5K-ma-ruf-segera-safari-ke-tangerang

Tahir, M. A. (2018). Politik Identitas dalam Pemilihan Kepala Daerah DKI Jakarta (Studi Analisis Wacana Terhadap Pidato Basuki Tjahaja Purnama di Kepulauan Seribu pada Tanggal 27 September 2016). (Skripsi). Medan: Universitas Sumatera Utara.

Yoedtadi M. G \& Pribadi M. A. (2017). Upaya Redaksi Televisi Menjaga Objektivitas Dalam Pemberitaan Pilkada DKI Jakarta. Jurnal Muara Ilmu Sosial, Humaniora dan Seni. 1(2). 275-285. 